\title{
Modelling sediment transport over partially non-erodible bottoms
}

\author{
F. Rulot*, ${ }^{*}$, B. J. Dewals, S. Erpicum, P. Archambeau and M. Pirotton \\ ArGenCo - MS $S^{2} F-H A C H$, University of Liège, Liège, Belgium
}

\begin{abstract}
SUMMARY
In-depth-averaged and cross-section-averaged morphodynamic models, based on explicit time integration, it may happen that the computed bed level becomes lower than the top level of a non-erodible layer (e.g. concrete, bedrock or armoured layer). This is a standard pitfall, which has been addressed in different ways. In this paper, we present an original approach for avoiding computation of non-physical bed levels, using an iterative procedure to correct the outward sediment fluxes. The procedure is shown to be computationally efficient while it achieves a high accuracy in terms of mass conservation. We compare our original approach with the existing Struiksma's method and with a reformulation of the problem in terms of mathematical optimization of a linear or nonlinear objective function under linear constraints.

The new procedure has been incorporated into an existing finite volume morphodynamic model. It has been validated with several $1 \mathrm{D}$ benchmarks leading to configurations with sediment transport over nonerodible bottom. The computation time has been verified not to increase by more than $15 \%$ compared with runs without non-erodible bottom. Copyright ( 2011 John Wiley \& Sons, Ltd.
\end{abstract}

Received 3 March 2011; Revised 29 July 2011; Accepted 16 August 2011

KEY WORDS: non-erodible bottom; computational method; sediment transport

\section{INTRODUCTION}

Sediment transport, specifically the relation between the sediment mass flux and the flow parameters, has been studied for approximately 200 years $[1,2]$. Nevertheless, in contrast with the shallow water equations model well established for the water flow, no fully satisfactory theory has arisen so far to describe the evolution of the bed profile [3]. Indeed, the differences in shapes and sizes of sediments in a specific river, give rise to complex stochastic sediment motion, which remains complicated to describe by a simple model. Yet, sediment transport can have critical consequences for sustainability of river systems, management of water resources as well as public safety. For instance, civil and environmental engineers face issues such as erosion after floods, sedimentation in reservoirs or dam breaching flows $[4,5]$. In order to deal correctly with these issues, the morphological models should be able to simulate a wide range of flow features and soil properties. In this paper, we focus on one of them: modelling sediment transport and morphodynamics in domains including both erodible (alluvial) and non-erodible (non-alluvial) areas. Non-erodible bottoms refer to all bottom areas, which may not be set in motion under given hydraulic conditions (i.e. bed rocks, concrete structure, armoured layers...). We analyse here mass-conservative modelling of bed-load transport in such configurations.

In literature, we found only few papers dealing specifically with this topic. Among them, Struiksma (1999) suggests a correction factor to reduce bed-load fluxes when the actual bed level approaches the non-erodible level. It however fails to keep the computed bed elevation above the non-erodible bottom and may therefore induce mass conservation errors.

*Correspondence to: F. Rulot, ArGenCo - MS ${ }^{2} \mathrm{~F}$ - HACH, University of Liège, Liège, Belgium.

†E-mail: Francois.Rulot@ulg.ac.be 
In the present paper, we introduce an original mass conservative iterative method, both simple and efficient, and we compare this new procedure with Struiksma's method. This method called the flux minimization method (FMM) in this paper is inspired by the correction method for the negative water depth in flow computation $[6,7]$.

We also reformulate the problem of handling partly non-erodible bottoms as a linear optimization problem with linear constraints. A rigorous mathematical solution of this formulation is computed using the simplex algorithm. This computation is computationally more expensive but is considered as a reference solution.

Next, our iterative procedure is shown to provide bed profile predictions consistent with the reference solution, with a computational time, which is at least one order of magnitude lower. It is also shown to perform better than Struiksma's method.

As a perspective, we show mathematically that our new procedure may also apply to handle the physical constraints on the concentration $(0 \leqslant C \leqslant 1)$ in suspended load modelling.

The mathematical and numerical model is first described (section 1) detailing the governing equations to which the three aforementioned methods have been applied. The methods are next comprehensively described (section 2) and evaluated on two benchmarks (section 3). A closing discussion highlights the main advantages provided by the FMM and suggests future developments.

\section{MATHEMATICAL AND NUMERICAL MODEL}

In this section, the derivation of a mathematical model for flow and morphodynamics is first detailed. The finite volume numerical technique applied to solve the set of governing equations is detailed in paragraph 2.4.

\subsection{From conservation laws to depth averaged equations}

Following an Eulerian description of the flow, conservation laws for the flow have been formulated in a Cartesian system of coordinates $(x, y, z)$, as sketched in Figure 1.

The $x$ and $y$ axes are chosen in such a way that the plane they define corresponds to the main flow direction. Axis $z$ is simply set normal to this plane.

Most flows of interest in civil and environmental engineering are characterized by significantly larger length scales in the $x-y$ plane (often almost horizontal) compared with the characteristic depth of the flow (often almost the vertical axis). As a result, the pressure is found almost hydrostatic along $z$ and depth averaged models may be used. Moreover, Navier-Stokes three-dimensional equations can be integrated over the local flow section. Accounting for proper kinematic and dynamic boundary conditions as well as a constant density $\rho$, this results in the following set of

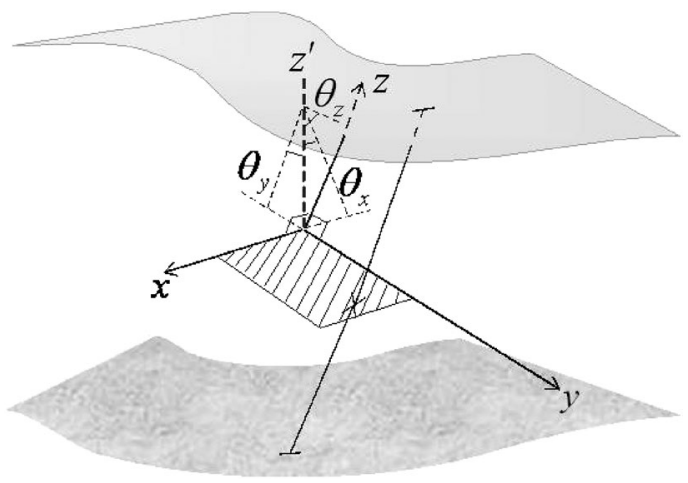

Figure 1. Axis of reference. 
one-dimensional equations:

$$
\begin{gathered}
\frac{\partial h}{\partial t}+\frac{\partial}{\partial x}(h \bar{u})=0 \\
\frac{\partial}{\partial t}(h \bar{u})+\frac{\partial}{\partial x}\left(h \bar{u}^{2}\right)=-\frac{g}{2} \frac{\partial h^{2}}{\partial x}-g h \frac{\partial z_{\mathrm{b}}}{\partial x}+\frac{1}{\rho} \frac{\partial h \bar{\sigma}_{x}}{\partial x}+\frac{\tau_{\mathrm{b} x}}{\rho} \Delta \Sigma
\end{gathered}
$$

Overbars denote depth-averaged quantities. $\rho=$ density of water; $t=$ time; $u=$ velocity components along $x ; g=$ gravity acceleration; $z_{b}=$ bed level; $\sigma_{x}=$ Reynolds normal stresses along $\mathrm{x}$-direction; $\tau_{b x}=$ shear stresses at the river bed and:

$$
\Delta \Sigma=\sqrt{1+\left(\frac{\partial z_{b}}{\partial x}\right)^{2}}
$$

Uniform velocity profile is assumed in these equations. Viscous stresses in the momentum equations have been neglected compared with Reynolds stresses because the latter greatly exceed the former in practical applications.

\subsection{Bed-load mass balance equation}

Besides the flow Equations (1)-(2), an additional mass balance equation for the bed-load is necessary to constitute the morphodynamic model. As sketched in Figure 2, two layers may be distinguished in the bed material. The lower layer consists of bed material at rest, while bed-load takes place in the upper layer. Sediment continuity for the bed-load material is simply expressed by the Exner equation:

$$
(1-p) \frac{\partial z_{\mathrm{b}}}{\partial t}+\frac{\partial q_{\mathrm{b} x}}{\partial x}=0
$$

Notation $q_{\mathrm{bx}}$ denotes the bed-load unit discharges along $x$. It can be expressed empirically in terms of a deterministic or a stochastic formula depending on parameters such as flow velocity, bed shear stress and so on.

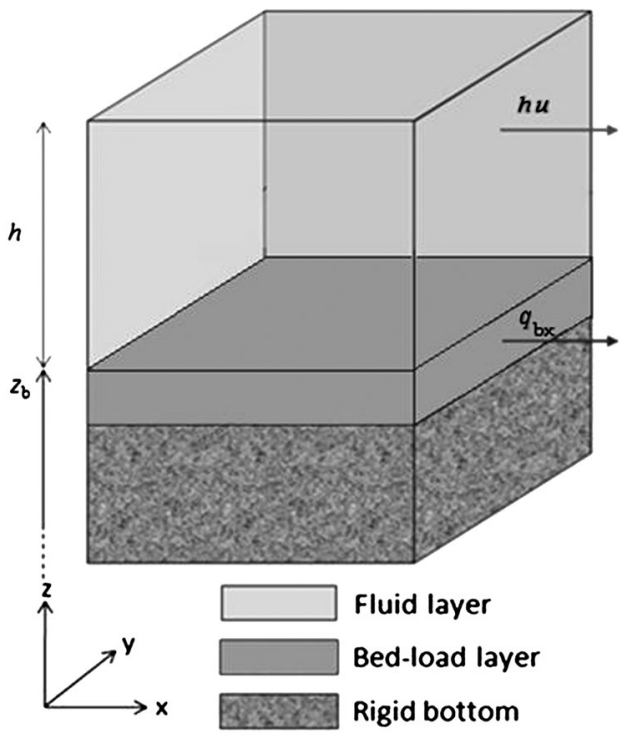

Figure 2. Schematic configuration underlying the depth-averaged morphodynamic model. 


\subsection{Summary of hydro-sedimentary equations}

Equations (1)-(4) can be rewritten in the following vector form:

$$
\frac{\partial \mathbf{s}}{\partial t}+\frac{\partial \mathbf{f}_{\mathrm{a}}}{\partial x}+\frac{\partial \mathbf{f}_{\mathrm{d}}}{\partial x}=\mathbf{r}
$$

with:

$$
\begin{gathered}
\mathbf{s}=\left[\begin{array}{lll}
h & h \bar{u} & (1-p) z_{\mathrm{b}}
\end{array}\right]^{T} \\
\mathbf{f}_{\mathrm{a}}=\left[\begin{array}{lll}
h \bar{u} & h \bar{u}^{2}+\frac{g h^{2}}{2} & q_{\mathrm{b} x}
\end{array}\right]^{T} \\
\mathbf{f}_{\mathrm{d}}=\left[\begin{array}{lll}
0 & \frac{h \bar{\sigma}_{x}}{\rho} & 0
\end{array}\right]^{\mathrm{T}}
\end{gathered}
$$

and $\mathbf{r}$ gathers all source terms.

The suspended sediment transport is neglected here.

\subsection{Space and time discretisation}

The computation domain is discretised by means of a regular Cartesian grid, thus having the benefits of regular grids in terms of order of accuracy, computation time and memory requirement.

The space discretisation of the divergence form of Equations (1)-(4) is performed by means of a finite volume scheme. Advective fluxes are computed by a flux vector splitting (FVS) method developed by the authors $[8,9]$. According to this FVS, the upwinding direction of the flux $\mathbf{f}_{\mathrm{a}}$ is simply dictated by the sign of the flow velocity reconstructed at the cells interfaces. Thus, it has the advantage of being completely Froude independent and of facilitating a satisfactory adequacy with the discretisation of the bed elevation gradient. It can be formally expressed as follows:

$$
\begin{gathered}
\mathbf{f}_{\mathrm{a}}^{+}=\left[\begin{array}{lll}
h \bar{u} & h \bar{u}^{2} & q_{\mathrm{b} x}
\end{array}\right]^{T} \\
\mathbf{f}_{\mathrm{a}}^{-}=\left[\begin{array}{lll}
0 & \frac{g h^{2}}{2} & 0
\end{array}\right]^{T}
\end{gathered}
$$

where the exponents + and - refer to, respectively, an upstream and a downstream evaluation of the corresponding terms. A Von Neumann stability analysis has demonstrated that this FVS leads to a stable spatial discretisation. Because of its diffusive nature, the flux $\mathbf{f}_{\mathrm{d}}$ is legitimately evaluated by means of a centred scheme.

The time integration is performed here by means of a Runge-Kutta algorithm. For stability reasons, the time step is constrained by the Courant-Friedrichs-Levy condition. A semi-implicit treatment of the bottom friction term (3) is used, without requiring additional computational cost.

\section{PROCEDURES TO HANDLE NON-ERODIBLE BOTTOMS}

Exner Equation (4) provides the evolution of the sediment level as a function of bed-load fluxes, evaluated by means of a transport capacity formula. However, when solving conventionally the Exner equation in presence of a partly non-erodible bed, it may happen that the computed values of the bed elevation are found to be below the top of the non-erodible layer. Therefore, additional constraints must be prescribed on the sediment fluxes; to verify everywhere $z_{b}>z_{b}^{F}$ where $z_{b}$ and $\mathrm{z}_{\mathrm{b}}^{\mathrm{F}}$ are the actual and non-erodible bed levels, respectively; while ensuring mass conservation. The following subsections introduce existing methods and an original approach to correct the sediment fluxes to account for a non-erodible layer, free of mass conservation error. 


\subsection{Existing method}

3.1.1. Struiksma method. A method for sediment routing on partially rigid bottoms was proposed by Struiksma [10]. It consists in modifying the customary deterministic bed-load transport formula $q_{b i}^{*}(h, u, v)$ (such as Meyer-Peter Müller, Schoklitsch, Bagnold, power law...) as follows:

$$
q_{b i}=\psi\left(\frac{\delta(x)}{\delta_{a}(h)}\right) q_{b i}^{*}(h, u, v),
$$

where $q_{b}$ and $q_{b}^{*}$ represent the actual sediment flux and the transport capacity, respectively. $\delta_{a}$ is the maximum thickness of alluvium for which the non-erodible layer still affects the sediment transport, $\delta$ is the actual thickness of alluvium (Figure 3) and $\psi$ is a function of $\delta / \delta_{a}$, which limits the bed-load transport flux because of the proximity of non-erodible areas. The thickness value $\delta_{a}$ is a case-dependent calibration parameter, which is reported to be approximately equal to half of the bed form height. For $\delta=0$, sediment transport is not possible anymore $(\psi=0)$; whereas for $\delta=\delta_{a}$, the presence of the non-erodible layer is considered to have no influence on the bed-load discharge $(\psi=1)$. Thus, the function $\psi$ monotonously increases between these two extreme values. The modified bed-load transport formula is then used in the Exner equation.

3.1.2. Optimization method. To construct a reference solution, we have reformulated the problem of correcting sediment fluxes to respect constraints of rigid bottom as an optimization problem with linear constraints. Following this reformulation, all bed-load fluxes are assumed to be modified by a correction factor $\alpha_{i}$ multiplying the flux $q_{b i}\left(i=1, N_{e}-N_{e b}\right)$ estimated from the transport capacity formula:

$$
q_{b i}=\alpha_{i} q_{b i}^{*}
$$

where $\mathrm{N}_{\mathrm{e}}$ is the total number of edges and $\mathrm{N}_{\mathrm{eb}}$ the number of edges where sediment inflow is prescribed as a boundary condition. The optimal set of values $\alpha_{i}$ should enable to respect the constraints of non-erodible bottom:

$$
z_{b i} \geqslant z_{b i}^{F}
$$

while keeping $q_{b i}$ as close as possible to $q_{b i}^{*}$ because it is considered as a good first guess. $z_{b i}$ represents the actual bottom elevation and $z_{b i}^{F}$ the level of the rigid bottom.

Two different approaches have been analysed.

First, if $q_{b i}$ is assumed to always remain lower than $q_{b i}^{*}$, the procedure may be mathematically formulated as a linear optimization problem:

$$
\begin{gathered}
\min _{\alpha_{i}} \sum_{i=1}^{N_{e}-N_{e b}}-\alpha_{i} \\
\text { with linear constraints : }\left\{\begin{array}{l}
0 \leqslant \alpha_{i} \leqslant 1 \\
z_{b i} \geqslant z_{b i}^{F}
\end{array}\right.
\end{gathered}
$$

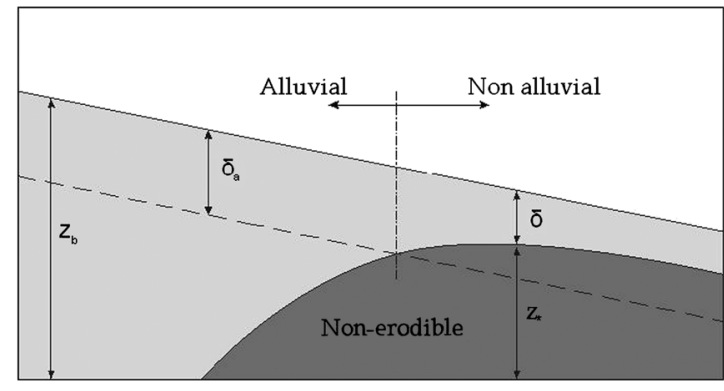

Figure 3. Definition of the concept of alluvial and non-alluvial areas [10]. 
In contrast, if, for the sake of generality, $q_{b i}$ is not assumed to remain lower than $q_{b i}^{*}$, the optimization problem involves the following nonlinear objective function:

$$
\begin{gathered}
\min _{\alpha_{i}} \sum_{i=1}^{N_{e}-N_{e b}}\left(1-\alpha_{i}\right)^{2} \\
\text { with linear constraints : }\left\{\begin{array}{l}
0 \leqslant \alpha_{i} \leqslant \alpha_{\max } \\
z_{b i} \geqslant z_{b i}^{F}
\end{array}\right.
\end{gathered}
$$

Obviously, the latter approach is more general, but it will be shown that it fails to properly reflect the actual physical behaviour of the morphodynamic system. The sum involved in the objective functions includes all fluxes except those on edges where the sediment inflow is prescribed as boundary condition. To solve these two optimization problems, existing algorithms have been used. In the first approach, the efficient simplex algorithm $[11,12]$ is used because both objective function and constraints are linear. In the second approach, an algorithm based on FORTRAN sequential quadratic programming was used: FFSQP [13].

\subsection{Flux minimization method}

Our original approach consists in an iterative procedure, in which corrections affect only the cells in which the computed sediment level is below the rigid bottom. This results in a considerably shorter CPU time compared with the optimization method described before. To ensure correct mass conservation in the resolution of Exner equation, a three-step procedure is used at each time step:

1. Equation (4) is evaluated (step 1 in Figure 4).

2. The algorithm checks in all cells whether the current sediment level, as obtained from Equation (4) is below the fixed bottom level; thus flagging occurrences of computed bed levels
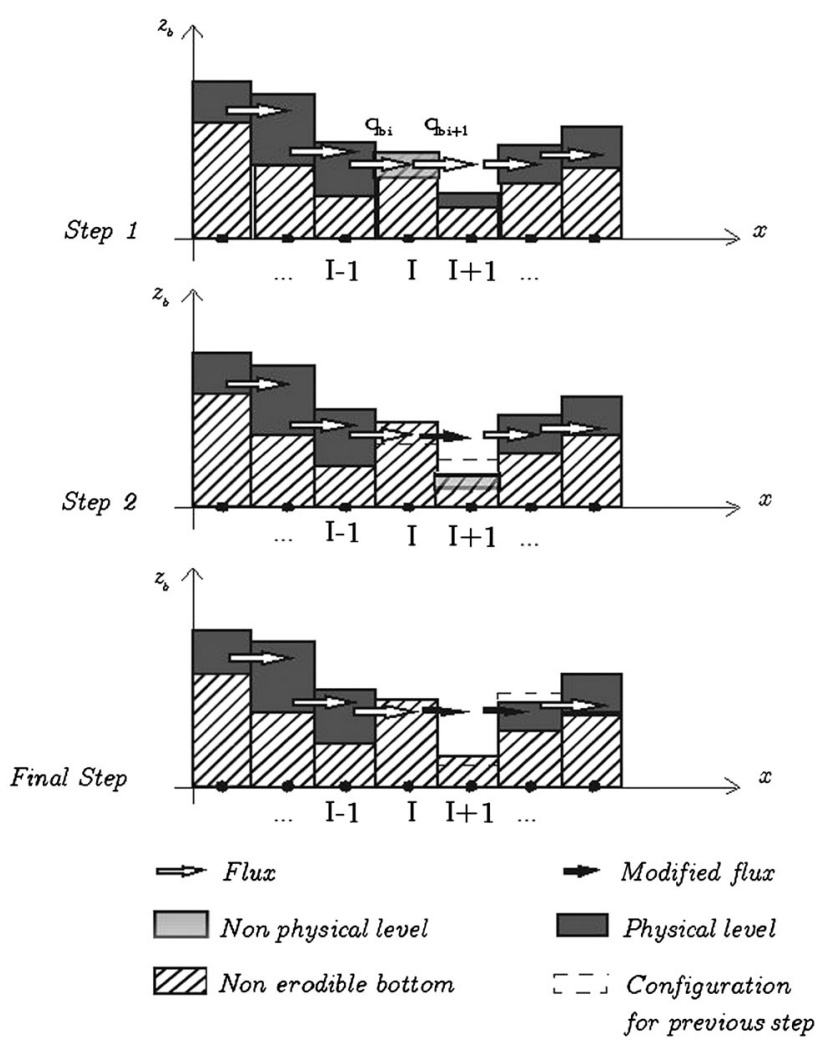

Figure 4. Three-step procedure. 
below the non-erodible bottom. Then, in cells with non-physical configurations, the outflow discharge $q_{b i}^{o u t *}$ is reduced (step 2 in Figure 4; dashed arrow) such that the computed bed level becomes strictly equal to the rigid bottom level $\left(q_{b i}^{\text {out }}=q_{b i}^{\text {out } *} \alpha\right)$. Regarding Figure 4, step 1, the parameter $\alpha$ is given by the following formula:

$$
\alpha=\frac{\Delta x(1-p)\left(z_{b I}^{F}-z_{b I}^{0}\right)}{\Delta t q_{b i+1}}+\frac{q_{b i}}{q_{b i+1}}
$$

where $\Delta x$ is the space step, $\Delta t$ the time step, $p$ the sediment porosity, ' $I$ ' refers to the index of the cell whereas ' $i$ ' refers to the index of the edges.

3. Because these flux corrections may in turn induce other non-physical configuration in neighbouring cells, steps 1 and 2 are repeated iteratively. This leads eventually to a configuration in which the levels are all in their physical range, as shown in the final step in Figure 4.

\section{VALIDATION}

The cross-section-averaged flow model combined with the algorithms of sediment flux correction have been verified and evaluated using several benchmarks leading to configurations with sediment transport over non-erodible bottoms. Three one-dimensional benchmarks are shown here: first, the scouring of a small basin initially filled with sediments; next, the migration of trenches passing over a fixed bump and, finally, the flushing in a uniform channel.

\subsection{Scour of a trench initially filled with sediments}

4.1.1. Description. A prismatic channel is considered here, with a 1.1-m-wide rectangular cross section. The length of the channel is $16 \mathrm{~m}$. The cell size is $0.2 \mathrm{~m}$. The rigid bottom corresponds to the level zero throughout the channel, except in a $4.5-m$-long trench located at mid-length of the channel, where the rigid bottom elevation is set to $-0.1 \mathrm{~m}$ [14]. This trench is initially filled with sediments up to the level zero (see Figure 5). In this hypothetical test case, the flow conditions are kept artificially constant in time. The flow discharge is assumed to increase linearly from $q\left(x_{0}\right)=0 \mathrm{~m}^{2} / \mathrm{s}$ to $q\left(x_{\text {mid }}\right)=10 \mathrm{~m}^{2} / \mathrm{s}$ between the abscissa $x_{0}=0 \mathrm{~m}$ and $x_{\text {mid }}=8 \mathrm{~m}$; and decrease linearly from $q\left(x_{\text {mid }}\right)=10 \mathrm{~m}^{2} / \mathrm{s}$ to $q\left(x_{\text {end }}\right)=0 \mathrm{~m}^{2} / \mathrm{s}$ between the abscissa $x_{\text {mid }}$ and $x_{\text {end }}=16 \mathrm{~m}$. The constant water depth is set everywhere equal to $h=2 \mathrm{~m}$. The Manning coefficient is taken equal to $n=0.04 \mathrm{~s} / \mathrm{m}^{1 / 3}$. The Engelund-Hansen bed-load transport formula is used in this case, in which the grain diameter is assumed equal to $d_{50}=0.3 \mathrm{~mm}$, the specific gravity of sediments is $s=2.65$, and the porosity of bed material is $p=0.375$.

4.1.2. Results. The computed time evolution of the bed profile is shown in Figure 5. After $100 \mathrm{~s}$, the bed profile does not move anymore. Although no direct comparison data are available, the model is

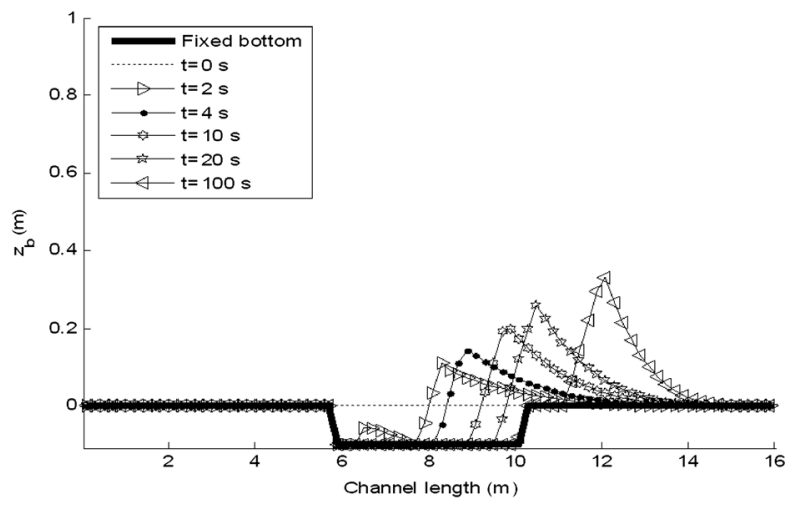

Figure 5. Bed evolution in the hyphothetical test case (FMM). 
found to perform satisfactorily because the constraints of non-erodible bed level is verified, whereas the volume conservation error is found to be nearly equal to the floating-point accuracy, as shown in Table I.

The three correction methods described in section 3 give similar results provided that $\delta_{\mathrm{a}}$ is small enough in Struiksma's method. The comparison of computational times (Table I) shows that the optimization method is almost 20 times slower than both original and Struiksma's method. For the optimization method and FMM, the computed bed level remains always above the level of the non-erodible bottom. However, Figure 6 reveals an irregularity in the result of Struiksma's method. Indeed, at $t=50 \mathrm{~s}$, the end of the sediment heap reaches the end of the small basin where there is a sudden increase in the fixed bottom level. At this location, Struiksma's method reduces excessively the inward discharge, leading to a strong local erosion in the next cell. Based on Equation (11), Struiksma's method fails indeed to strictly ensure that the sediment level remains always above the non-erodible bottom level. This leads inevitably to a sediment volume loss (Table I). This is considered as the main drawback of Struiksma's method.

\subsection{Evolution of a trench over a fixed bump}

4.2.1. Description. This test case considers the evolution of a trench passing over a non-erodible bump. The length of the straight channel is $11.5 \mathrm{~m}$, and its width is $0.2 \mathrm{~m}$. The cell size is $0.1 \mathrm{~m}$. The discharge is $9.2 \mathrm{l} / \mathrm{s}$, the water depth is $0.106 \mathrm{~m}$, and the water surface slope is $1.75 \mathrm{~mm} / \mathrm{m}$. A bump is located in the middle of the domain, whereas an approximately $0.06-m$-deep and $2-m$-long trench (Test 1) or $0.04-m$-deep and $2-m$-long trench (Test 2 ) are excavated in the alluvial bed upstream. Note that the trenches are not exactly the same within the two tests developed hereafter. The grain diameter is equal to $0.45 \mathrm{~mm}$ and the bottom Chézy friction coefficient is $31.8 \mathrm{~m}^{1 / 2} / \mathrm{s}$. The bedload transport capacity formula is assumed to be a power function of the water velocity: $q_{b}=m u^{5}$ where $m=3.610^{-4} s^{4} / m^{3}$ (test $n^{\circ} 1$ ) and $m=4.010^{-4} s^{4} / m^{3}$ (test $\mathrm{n}^{\circ} 2$ ). Coefficient $m$ was used as a tuning parameter to reproduce the propagation of the front of the trench over the first $2 \mathrm{~m}$ in the upstream section [10]. The upstream sediment transport, including pores, is $q_{b, \text { upstream }}=4.0 \mathrm{l} / \mathrm{h}$ (test $\mathrm{n}^{\circ} 1$ ) and $q_{b, \text { upstream }}=4.4 l / h$ (test $\mathrm{n}^{\circ} 2$ ). Two experiments were carried out. In Test $\mathrm{n}^{\circ} 1$, the thickness of alluvium on the bump is small whereas in test $n^{\circ} 2$, the thickness is zero. The shapes of the fixed bumps and the trenches also differ between test $\mathrm{n}^{\circ} 1$ and test $\mathrm{n}^{\circ} 2$.

Table I. Volume conservation and CPU time comparison for the three methods.

\begin{tabular}{lccc}
\hline & FMM & Struiksma's method & Optimization method \\
\hline Volume conservation error $\left(\Delta \mathrm{V} / \mathrm{V}_{\text {init }}\right)$ & $1.4 \times 10^{-13}$ & $4.2 \times 10^{-9}$ & $4.6 \times 10^{-13}$ \\
CPU time compared to the FMM & 1 & 0.89 & 18.33 \\
\hline
\end{tabular}

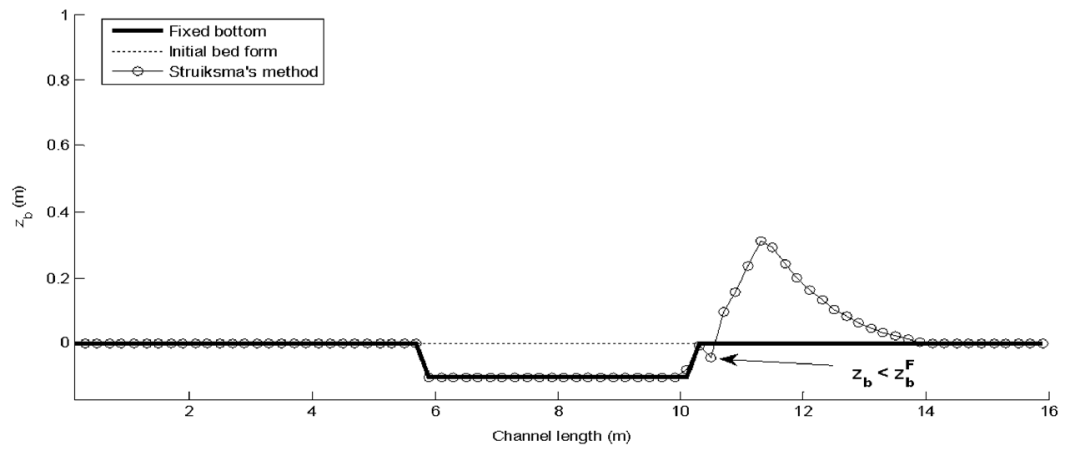

Figure 6. Non-erodible condition not met by Struiksma's method at time $\mathrm{t}=50 \mathrm{~s}$. 
4.2.2. Results. Comparisons between numerical and experimental results are shown in Figure 8. For both test-cases, experimental data [10] are scattered, but the overall agreement with numerical predictions is found satisfactory. Two statistical parameters have been used to quantify the goodness-of-fit between computed and measured bed profiles namely the bias, and the root-mean-square $(R M S)$ [15]. They are described as follows:

1. The bias measured in unit of length is the arithmetic mean of the difference between computed and experimental bed profiles:

$$
\text { bias }=\sum_{j=1}^{N_{m p t s}} \frac{z_{b, c}(j)-z_{b, m}(j)}{N_{m p t s}}
$$

where $z_{b, c}$ and $z_{b, m}$ are, respectively, the computed and measured bed profile whereas $N_{m p t s}$ is the number of experimental measurement points. A positive value of this parameter indicates that the computed bed profile generally overestimates the measured bed profile.

2. The RMS represents the quadratic mean difference between the computed and measured bed profiles:

$$
R M S=\sqrt{\sum_{j=1}^{N_{m p t s}} \frac{\left(z_{b, c}(j)-z_{b, m}(j)\right)^{2}}{N_{m p t s}}}
$$

This parameter reflects the absolute value of the difference between both bed profiles.

RMS parameter remains everywhere lower than $1 \mathrm{~cm}$ (Figure 7), showing that dissimilarities between measured and computed bed profiles are rather small in all three methods. The bias shows that computed bed profile generally underestimates on average the experimental data for the bed profile for all three methods.

Looking deeper into the details (Figure 8), computations overpredict erosion depth downstream of the non-erodible bump for both tests. This may result from the simplified transport capacity formula used, accounting neither for an explicit threshold for transport inception nor for gravity-induced sediment transport. Vertical accelerations might also play a part in this region. Results of test $n^{\circ} 1$ and test $n^{\circ} 2$ also reveal that the computed sediment level on the bump is underpredicted. The deeper sediment layer found experimentally may result from the medium gravels used to build the bump (non-erodible under considered hydraulic conditions) leading to a higher bed roughness, which is not accounted for. The CPU time comparison (see Table II) shows once more that the time needed by the optimization method is fairly greater than the time needed by both other methods, whereas no difference is found between the results of the optimization method and the original one.
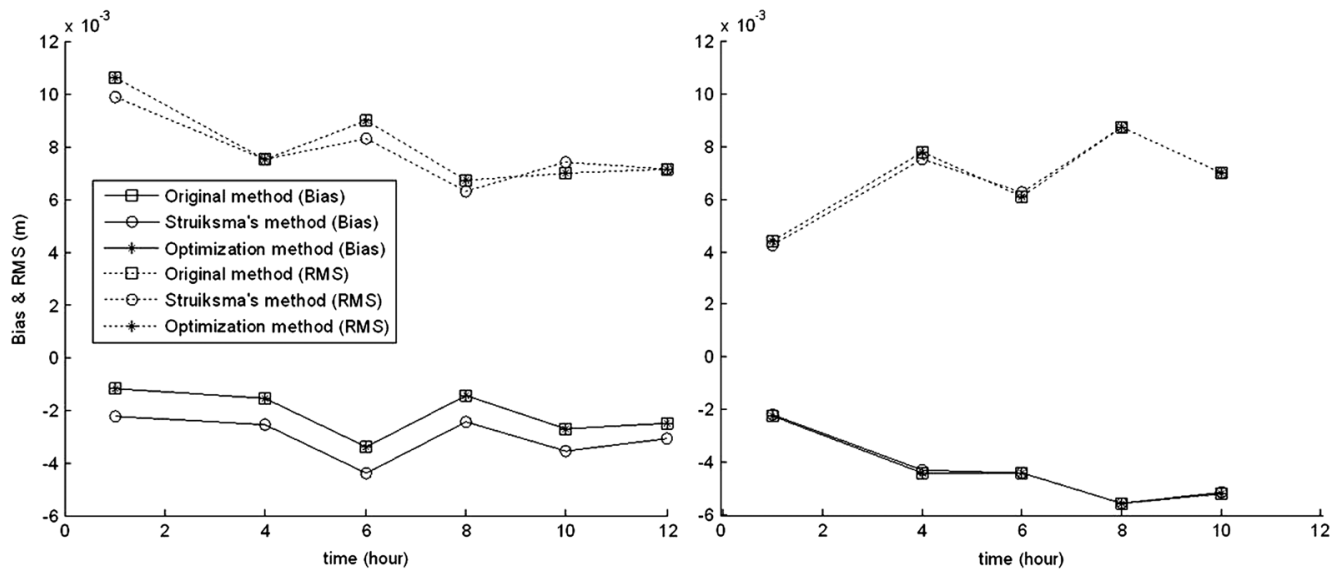

Figure 7. Bias and RMS for test $n^{\circ} 1$ (left) and test $n^{\circ} 2$ (right). 

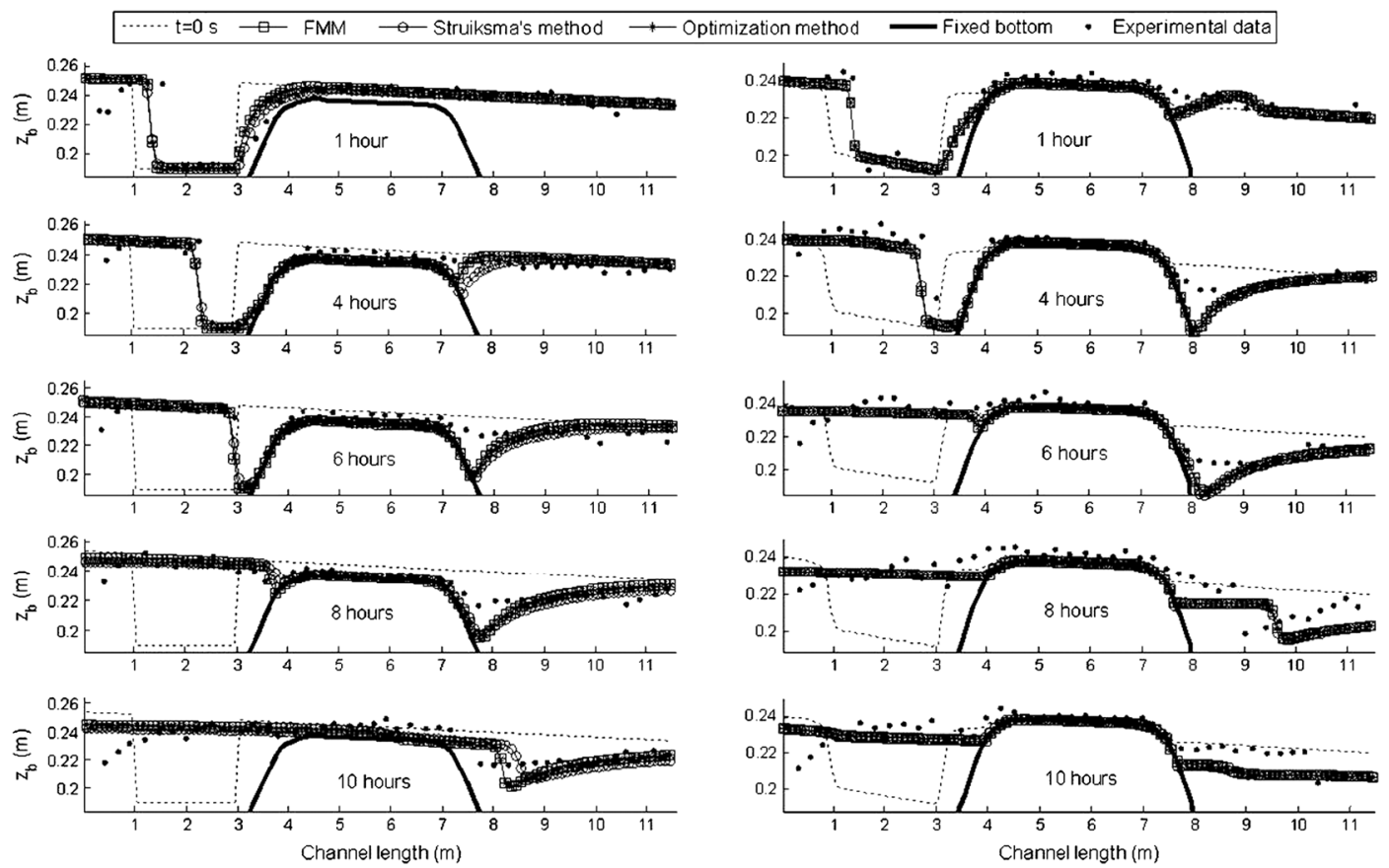

Figure 8. Time evolution of the longitudinal bed profiles (T1, left and T2, right).

Table II. Volume conservation and CPU time comparison for the three methods.

\begin{tabular}{|c|c|c|c|c|c|c|}
\hline \multirow[b]{2}{*}{ Method } & \multicolumn{3}{|c|}{ Test $n^{\circ} 1$} & \multicolumn{3}{|c|}{ Test $\mathrm{n}^{\circ} 2$} \\
\hline & FMM & Struiksma & Optimization & FMM & Struiksma & Optimization \\
\hline $\begin{array}{l}\text { Volume conservation } \\
\text { error }\end{array}$ & $5.6 \times 10^{-11}$ & $5.9 \times 10^{-11}$ & $5.6 \times 10^{-11}$ & $2.2 \times 10^{-11}$ & $2.1 \times 10^{-11}$ & $2.2 \times 10^{-11}$ \\
\hline $\begin{array}{l}\text { CPU time compared } \\
\text { to the FMM }\end{array}$ & 1 & 0.73 & 14.64 & 1 & 0.93 & 16.34 \\
\hline
\end{tabular}

\subsection{Flush in a uniform channel}

4.3.1. Description. The flush in a uniform channel is an interesting test case because it highlights the non-directionality aspect of the FMM method. Indeed, the method is applicable both for corrected areas from the upstream to the downstream and for corrected areas from the downstream to the upstream as shown hereafter. The computational domain is $L=30 \mathrm{~m}$ long. The space step in the longitudinal direction is $\Delta \mathrm{x}=0.3 \mathrm{~m}$. At the beginning, a uniform flow takes place, in which the water depth is equal to $h=1 \mathrm{~m}$, the water discharge is $q=1 \mathrm{~m}^{2} / \mathrm{s}$, the bed slope is $6.9210^{-2} \mathrm{~mm} / \mathrm{m}$ and the Manning friction coefficient is $n=0.0222 \mathrm{~s} / \mathrm{m}^{1 / 3}$. The sediment porosity is fixed to $p=0.375$. The bed is made of erodible sediments except in the most downstream $9 \mathrm{~m}$ where the bottom is non-erodible. The bed-load transport $q_{b}$ is assumed to follow a similar power law as in the previous test case, with $m=1.4510^{-2} \mathrm{~s}^{4} / \mathrm{m}^{3}$.

At time $t=0 \mathrm{~s}$, the downstream boundary condition on free surface height is suddenly changed to $z_{s, \text { downstream }}=0.7 \mathrm{~m}$ instead of $z_{s, \text { downstream }}=1 \mathrm{~m}$ (Figure 9 ). This leads to an increase in the flow velocity, which results in turn in a degradation of the erodible part of the bed. After a certain time, the morphodynamic and hydraulic conditions reach a new equilibrium state.

4.3.2. Results. This benchmark is used to test the second approach (Equation (16)) of the optimization method. After $4 \mathrm{~s}$, erosion is found in the part upstream of the non-erodible area Figure 10. Approach $n^{\circ} 2$ leads to more erosion than approach $n^{\circ} 1$ (Equation (14)). For clarity, results of the FMM have not been included in Figure 10 because they fit exactly the results of the first approach of 


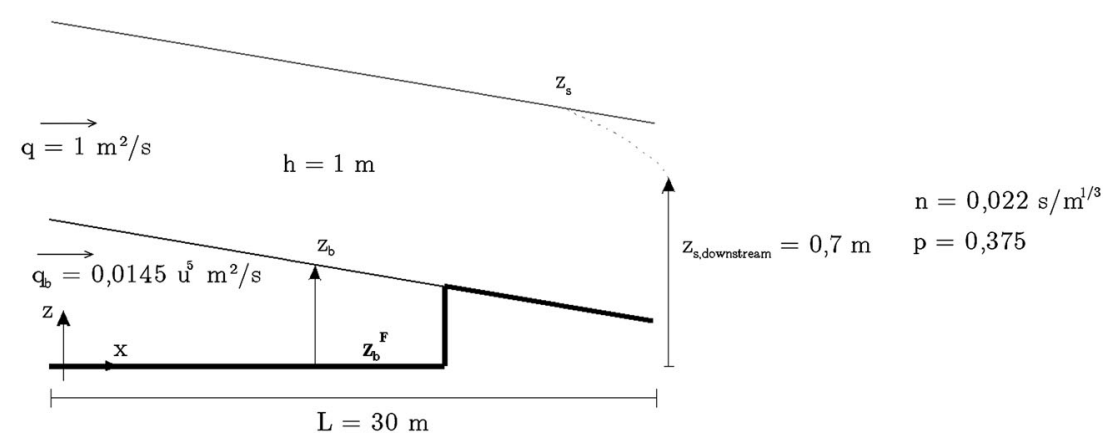

Figure 9. Sketch of the idealized flushing configuration.

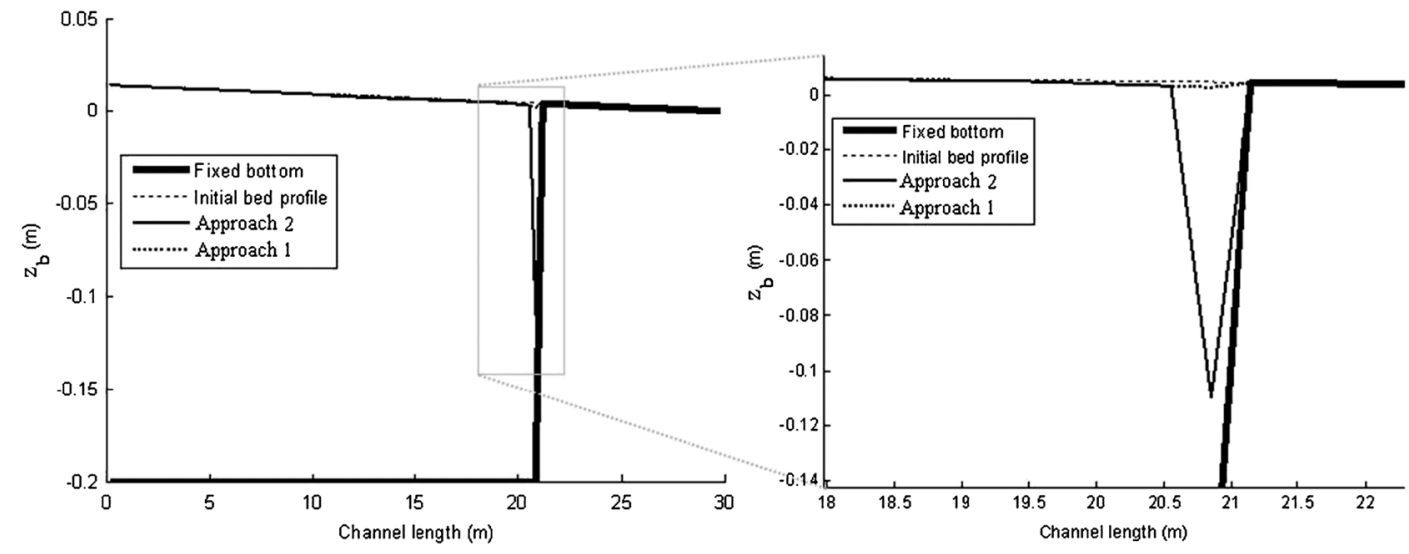

Figure 10. Bed profile after $4 \mathrm{~s}$ obtained with both optimization methods.

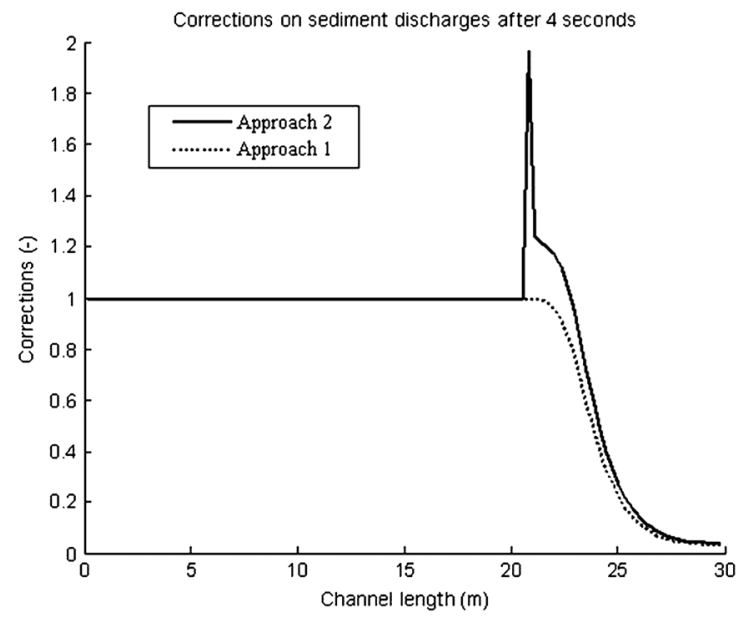

Figure 11. Correction factor $\alpha$ on bed-load discharge.

optimization. As shown in Figure 11, the computed correction coefficients of the bed-load discharge are found greater than one. This is in complete contradiction with the physical observations, which suggest that the bed-load discharge on non-alluvial beds is decreased compared with the situation without non-erodible layer. Indeed, in such locations, the bed-load layer gets thinner because of the presence of the non-erodible bottom so that it leads to smaller volumes of bed-load and in turn to smaller bed-load discharges. Approach $\mathrm{n}^{\circ} 2$ provides a mathematical solution to the problem, but this solution turns out to be unphysical. In contrast, the first approach, in which the correction parameter 
Table III. Problems for which FMM can be applied.

\begin{tabular}{lccc}
\hline General & Rigid bottom & Drying cells & Suspended load \\
\hline$s$ & $z_{b}$ & $h$ & $C$ \\
Fluxes & $q_{b x}, q_{b y}$ & $h u, h v$ & $h C u, h C v$ \\
Constraints & $z_{b}>z_{b}^{F}(x, y, t)$ & $h>0$ & $0<C<C_{\text {max }}$ \\
\hline
\end{tabular}

is imposed lower than one, appears more appropriate. Therefore, only approach $\mathrm{n}^{\circ} 1$ may reasonably be applied.

The first optimization approach is obviously the most objective one because it relies on the most rigorous mathematical formulation and resolution of the problem, and has therefore been considered as a reference. However, the second benchmark showed that this method is far more costly in CPU time than both our FMM and Struiksma's methods.

\section{DISCUSSION}

Struiksma's method and FMM are both interesting in terms of CPU time. The differences of these two methods appear when the thickness of the alluvium is less than the specified maximum thickness $\left(\delta<\delta_{\mathrm{a}}\right)$. At this point, the algorithm in Struiksma's method begins to correct bed-load discharge whereas FMM only corrects the bed-load discharge when the non-erodible bottom is reached. It follows that the thin sediment layer had a damping effect caused by sediment depletion in Struiksma's method [16] whereas the effect is direct in FMM. However, Struiksma's method does not always respect the rigid bottom constraint. Indeed, when strictly applying the formula (11), we may have in some cells $z_{\mathrm{b}}<z_{\mathrm{b}}^{\mathrm{F}}$ whereas FMM formula (18) always respects this inequality. Furthermore, the maximum thickness $\left(\delta_{\mathrm{a}}\right)$ of alluvium for which the non-erodible layer still affects the sediment transport may vary with several parameters $\left(h, F r\right.$, bed form, $\left.d_{50} \ldots\right)$ and thus remains difficult to predict, as it may also vary with time and space. In order to use the advantages of each method, a combination of the two methods can be imagined. However, Struiksma's method is not made for an iterative method because the correction factor (11) is a function of the water depth, Froude number; these parameters do not vary between iteration; thus the correction factor does not vary too. Thus, the alternative idea could be to limit the correction factor in the same way as that of the original method and taking into account of a damping effect, but this method has been proved to be less accurate than that of the original method. In brief, it is advised to use the FMM when dealing with sediment transport over partially non-erodible bottoms because it provides an appealing trade-off between accuracy and computational efficiency. In addition, in the considered 1D benchmarks, the optimization method and FMM give identical results.

Whereas the methods described in section 3 apply for bed-load transport, our original approach has also been used to solve, free of mass conservation error, other problems in which the dependant variable in the continuity equation may be constrained (Table III). On the one hand, our original iterative approach has been used so far in a number of flow studies involving wetting and drying of cells $[6,17,18]$. On the other hand, it may also apply for suspended load modelling accounting for a variation range of the concentration bounded by zero and a saturation concentration.

When both bed load and suspended sediment load are involved, the approach also enables to account for the exchange term between bed and flow layers. Indeed, because of the non-erodible layer, the sediment exchange may be reduced as a result of impoverishment of the bed-load layer for instance. This is definitely a topic for further research. In addition, the bed-load layer $\delta_{\mathrm{a}}$ effect in Struiksma's method could also advantageously be combined with the FMM.

\section{CONCLUSIONS}

Relying on a validated mathematical and numerical model to describe the flow and bed-load transport, an original algorithm has been developed in order to handle sediment transport on partly non-erodible bottoms. This method has been compared with two others, namely an optimization 
method and Struiksma's method. The FMM has proved its efficiency in terms of computational time as well as for respecting a non-erodible bottom constraint, while enabling to verify the sediment mass conservation at the floating point accuracy.

\section{NOMENCLATURE}

\begin{tabular}{|c|c|}
\hline$C$ & Suspended load concentration \\
\hline$C_{\max }$ & Maximum value of the suspended load concentration \\
\hline$d$ or $d_{50}$ & Mean grain diameter \\
\hline $\mathbf{f}_{a}$ & Vector of advective fluxes \\
\hline $\mathbf{f}_{d}$ & Vector of diffusive fluxes \\
\hline $\mathrm{Fr}$ & Froude number \\
\hline$g$ & Gravity acceleration \\
\hline$h$ & Water depth \\
\hline$i$ & Edges index \\
\hline$I$ & Cells index \\
\hline$L$ & Length of the domain \\
\hline$n$ & Manning's coefficient \\
\hline$N_{e}$ & Total number of edges in the discretised space \\
\hline$N_{e b}$ & $\begin{array}{l}\text { Number of edges in the discretised space where sediment inflow is prescribed as a } \\
\text { boundary condition }\end{array}$ \\
\hline$N_{m p t s}$ & Number of experimental measurement points \\
\hline$p$ & Porosity of alluvium \\
\hline$q$ & Water discharge \\
\hline$q_{b}^{*}$ & Customary bed-load discharge \\
\hline$q_{b}^{O U T *}$ & Customary outward bed-load discharge \\
\hline$q_{b, \text { upstream }}$ & Upstream boundary condition for bed-load transport \\
\hline$q_{b x}$ & Bed-load discharge in $x$-direction \\
\hline$q_{b y}$ & Bed-load discharge along $y$-direction \\
\hline $\boldsymbol{r}$ & Vector of source terms \\
\hline$s$ & Relative density between sediment and water \\
\hline$s$ & Vector of unknowns \\
\hline$t$ & Time \\
\hline$u$ & Velocity in $x$-direction \\
\hline$v$ & Velocity in $y$-direction \\
\hline$V_{\text {init }}$ & Initial sediment volume \\
\hline$x$ & First spatial direction \\
\hline$y$ & Second spatial direction \\
\hline$z$ & Third spatial direction \\
\hline$z_{b}$ & Bed level \\
\hline$z_{b}^{F}$ & Non-erodible bed level \\
\hline$z_{b, c}$ & Computational value of the sediment level \\
\hline$z_{b, m}$ & Measured value of the sediment level \\
\hline$z_{s, \text { downstream }}$ & Downstream free surface level (boundary condition) \\
\hline$\alpha$ & Correction factor of the computed bed-load discharge \\
\hline$\alpha_{\max }$ & Maximum value of correction factor \\
\hline$\delta$ & Actual thickness of alluvium \\
\hline$\delta_{a}$ & $\begin{array}{l}\text { Maximum thickness of alluvium for which the non-erodible layer still affects the } \\
\text { sediment transport }\end{array}$ \\
\hline$\Delta x$ & Space step \\
\hline$\Delta t$ & Time step \\
\hline$\Delta V$ & Sediment volume variation between initial and final state \\
\hline$\Delta \Sigma$ & Surface increase on which shear stress occurs \\
\hline
\end{tabular}


Water density

Reynolds normal stresses along $\mathrm{x}$-direction

Shear stress at the river bed

$\psi$

Function of $\delta / \delta_{\mathrm{a}}$ which limits the bed-load transport flux caused by the proximity of non-erodible areas

\section{REFERENCES}

1. Frey P, Church M. How river beds move. Science 2009; 325:1509-1510.

2. Graf WH. Hydraulics of Sediment Transport. Water Resources Publication: Highlands Ranch, Colorado, USA, 1984.

3. Spasojevic M, Holly FM. Two- and three-dimensional numerical simulation of mobile-bed hydrodynamics and sedimentation. In Sedimentation Engineering: Processes, Measurements, Modeling, and Practice, Marcelo HG (ed.). American Society of Civil Engineers: Reston, Virginia, USA, 2008; 683-761.

4. Dewals BJ, Rulot F, Erpicum S, Archambeau P, Pirotton M. Design Concept - Long-term sediment management for sustainable hydropower. In Comprehensive Renewable Energy. Volume 6 - Hydro Power, Sayigh A (ed.). Elsevier: Oxford, 2010.

5. van Rijn LC. Unified view of sediment transport by currents and waves. I: Initiation of motion, bed roughness, and bed-load transport. Journal of Hydraulic Engineering 2007; 133:649-667.

6. Dewals BJ, Rulot F, Erpicum S, Archambeau P, Pirotton M. Advanced topics in sediment transport modelling: non-alluvial beds and hyperconcentrated flows. In Sediment Transport. InTech: Rijeka, Croatia, 2011; 1-30.

7. Paulus R, et al. Dam Break Flow Modelling and Geographical Distribution of the Roughness Coefficient. In 33rd IAHR congress : water Engineering for a Sustainable Environment. IAHR, 2009.

8. Erpicum S, Dewals BJ, Archambeau P, Pirotton M. Dam-break flow computation based on an efficient flux-vector splitting. Journal of Computational and Applied Mathematics 2010; 234:2143-2151.

9. Dewals BJ, Kantoush SA, Erpicum S, Pirotton M, Schleiss AJ. Experimental and numerical analysis of flow instabilities in rectangular shallow basins. Environmental Fluid Mechanics 2008; 8:31-54.

10. Struiksma N. Mathematical modelling of bedload transport over non-erodible layers. In Proceedings of IAHR Symposium on River, Coastal and Estuarine Morphodynamics. IAHR: Genova, 1999; 6-10.

11. Bixby RE. Implementing the simplex method: the initial basis. Journal on Computing 1992; 4:267-284.

12. Andersen ED, Andersen KD. Presolving in linear programming. Mathematical Programming 1995; 71:221-245.

13. Lawrence CT, Tits AL. Nonlinear equality constraints in feasible sequential quadratic programming. Optimization Methods and Software 1996; 6:265.

14. Hervouet J, Machet C, Villaret C. Calcul des évolutions sédimentaires : le traitement des fonds rigides. Revue européenne des éléments finis 2003; 12:221-234.

15. Chen D, Acharya K, Stone M. Sensitivity analysis of nonequilibrium adaptation parameters for modeling mining-pit migration. Journal of Hydraulic Engineering 2010; 136:806-811.

16. Sloff CJ. Mixed alluvial and non-alluvial bed topographies: observations modeling and implications. In River Flow 2010, Dittrich, Koll, Aberle \& Geisenhainer. Bundesanstalt für Wasserbau, 2010.

17. Roger S, et al. Experimental and numerical investigations of dike-break induced flows. Journal of Hydraulic Research 2009; 47:349-359.

18. Erpicum S, Dewals BJ, Archambeau P, Detrembleur S, Pirotton M. Detailed inundation modelling using high resolution DEMs. Engineering Applications of Computational Fluid Mechanics 2010; 4:196-208. 